\title{
Feather loss in a budgie
}

\section{Abstract}

A 3 years old budgie with the complaint of feather loss and disturbed body growth, was referred to the clinic. In history, it was understood that two offspring showed healthy growth within the first year of their life, then scaling on the skin was observed in one of the budgie's feet. Over the next 3 months the body feathers began to fall. In the hairless regions, new feathers appeared in a cottony look and weak structure. But these new feathers shed before they could finish growing. The food and water appetite had not deteriorated during this time.

In physical examination, there were a few feather in cotton appearance on the body of the budgie. Bird had difficulty in balancing his body while standing and walking. Nowhere in the bird's body has skin lesions. In mycological culture, Aspergillus spp. was isolated. Bird died a week after being brought to the clinic.

When the etiology of the disease is assessed in the budgies $>3$ years old, all feathers have fallen and body development has deteriorated, it has been concluded that it is appropriate to consider chronic diseases which cause weakening of the immune system resulting in diseases such as aspergillosis.

Key Words: Budgie, Feather-loss
Arif Kurtdede ${ }^{1}$

Mehmet Kazim Börkü ${ }^{1}$

Nevra Keskin ${ }^{1}$

Nurdan Karacan ${ }^{2}$

${ }^{1}$ Veterinary Medicine, Department of Internal Medicine, Ankara University

${ }^{2}$ Veterinary Medicine,

Department of Microbiology, Dicle University

Correspondence

Arif KURTDEDE

akurtdede@ankara.edu.tr

Article Info

Received: 02-02-2018

Accepted: 19-03-2018 


\section{Introduction}

Hair loss in cage birds is a common disorder. It is difficult to identify the causes of primary and secondary causes of hair loss. In the diagnosis, it is important to assess the patient's detailed anamnesis, physical examination of the patient, macro- and microexaminations of hair and skin specimens in the lesion area, and diagnostic test results (Lawton, 2000; Greenberg, 2006; Rubinstein and Lightfoot, 2014).

In this case report, it was aimed both to emphasize that a budgie was able to survive for 2 years, completely without feather and to comment clinical value of the excess Aspergillus spp. growth in the skin surface.

\section{Case History}

A budgie was brought to the clinic with the complaint that all the feather on his body had fallen, and it had been in a hairless condition for two years. In the anamnesis, the animal owner said that the growth of two puppy budgies was normal for one year after leaving the egg, then scaling on the skin was observed in one of the budgie's feet. Over the next 3 months the body feathers began to fall. In the hairless regions, new feathers appeared in a cottony look and weak structure. But these new feathers shed before they could finish growing. The sick bird has lived for 2 years without feather and, the food and water appetite had not deteriorated during this time. In the physical examination, the budgie's body had a few cotton feathers in a cotton-like look. It was having difficulty balancing his body while standing and walking. There was no skin lesion anywhere in it's body. The skin swap specimen taken from the budgie was cultured in Sabouraud Dextrose Agar and this agar was incubated for 7 days at $25^{\circ} \mathrm{C}$ under aerobic conditions. Mycological growth began from the fourth day. Culture sample was stained with Lactophenol cotton blue and examined by light microscopy, and Aspergillus spp. was isolated. It was learned that budgie died a week after being brought to the clinic.

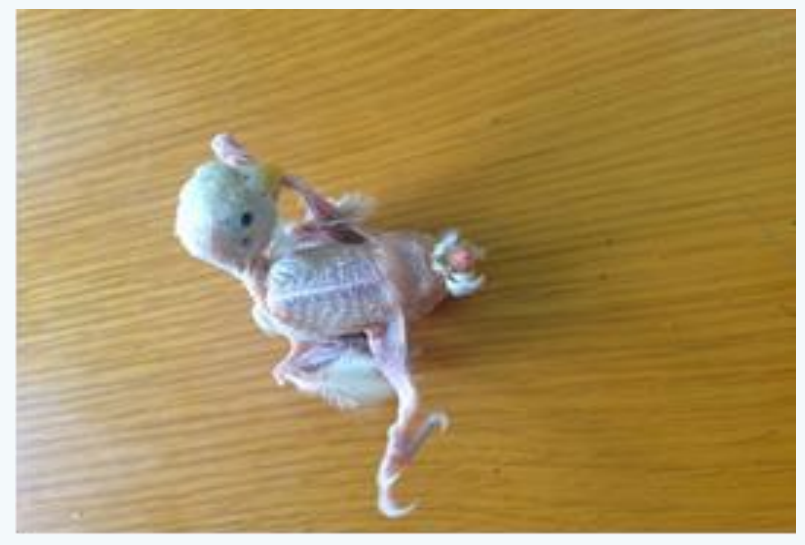

Figure 1: A 3 years old bugie.

\section{Discussion}

Hair loss in cage birds is a multi-factorial disorder. It occurs in diseases affecting the body, in inappropriate environment and nutritional conditions, and for psychological reasons. Hair replacement disorders can occur as a consequence of illnesses, as well as the lack of proper hair replacement period (Rubinstein and Lightfoot, 2014). In feather-loss birds, it is important to take good anamnesis in order to be successful in treatment and to monitor the effect of medical practices carefully (Greenberg, 2006; Lawton, 2000).

Similar to the descriptions of the researchers (Harris and Oglessbe, 2006), in this case report; the etiology of hair loss that occurred during the age of 1 year in one of the two budgies raised on the same conditions could not be established. Abundant Aspergillus spp. grew in the mycological culture of the skin surface swab.

Similar to the case of Psittacine beak and feather disease (PBFD), which has been shown to result in weakening of the immunizing system resulting from thymus and bursa destruction (Harcourt-Brown, 2000; 
Harris and Oglessbe, 2006), in this presentation of the budgie with feather-loss and feather-growth disorder, isolation of the abundant Aspergillus spp. in the agar in the skin swap samples, gave us suggestion that in this sick budgie there may be deficiency in the immunity system.

Harris and Oglessbe (2006), have remarked that the chronic form of PBFD disease is seen in birds under the age of 3 , and these budgies have lived for months or years without deteriorating his overall health, and death from PBFD was the results of secondary bacterial, viral and fungal infections or general health status impairment. With the above explanations, the clinical findings based on the anamnesis information of the budgie in this presentation are compatible.

There were no similarities between the clinical signs of polyomavirus infection (Harris and Oglessbe, 2006) that are the flight feathers-loss, abdominal-crop swelling and subcutaneous bleeding, and the clinical findings in the budgie in this presentation.

As a result, when budgies under 3 years of age exhibits feather-losses and feather development disorders in all body areas, it would be appropriate to take into account the chronic diseases, that causes weakness in the immunization system resulting in the diseases such as Aspergillosis.

\section{References}

Greenberg, T.B. (2006). Avian Dermatology. In: Saunders Manual of Small Animal Practice. Birchard SJ, Sherding RG (edts), Third ed. Elsevier Inc. USA, 1758- 1771.

Harcourt-Brown, N.H. (2000). Psittacine birds. In: Handbook of Avian Medicine, Tully TN, Dorristein GM ve Jones AK (Edts.), second ed. W. B. Saunders, Philadelphia, USA, 112-143.

Harris, D.J., Oglessbe, B.L. (2006). Avian Infectious Diseases. In: Saunders Manual of Small Animal Practice.
Birchard SJ, Sherding RG (edts), Third ed. Elsevier Inc. USA. 1740- 1757.

Lawton, M.P.C. (2000). The Physical examination. In: Handbook of Avian Medicine, Tully TN, Dorristein GM ve Jones AK (Edts.), second ed. W. B. Saunders, Philadelphia, USA, 26-42.

Rubinstein. J., Lightfoot, T. (2014). Feather Loss and Feather Destructive Behavior in Pet Birds, Veterinary Clinics: Exotic Animal Practice, 17(1), 77-101. 